\title{
Deporte sociomotriz y formación integral en estudiantes de bachillerato de la UAA
}

\author{
Roberto Romo Marín
}

\section{Resumen}

$\tau$ os ejes rectores de la Universidad Autónoma de Aguascalientes (UAA) impulsan tanto el desarrollo de actividades de índole académica y científica, como de orden deportivo, artístico y cultural. En este sentido, "La UAA concibe la educación como un proceso intencional y sistemático, cuya finalidad es la formación integral de la persona, esto es, el desarrollo pleno de todas sus facultades" (UAA, 2007: 5). Para lograr este propósito, promueve un programa de actividades de orden deportivo, principalmente de tipo sociomotriz, que aporta beneficios en el despliegue integral de la personalidad de los estudiantes pertenecientes al Centro de Educación Media (CEM), además de la adquisición de hábitos saludables, el uso positivo del tiempo libre, la vigorización física, la convivencia y la vida en sociedad, entre otros valores del deporte estudiantil.

Palabras clave: educación media superior, Modelo Educativo Institucional, formación integral, deporte estudiantil, sociomotricidad.

\section{Introducción}

De acuerdo con el Nuevo Modelo Educativo para la Educación Obligatoria ${ }^{1}$ de la Secretaría de Educación Pública (SEP, 2017b: 59): "La educación es un derecho que debe tender al desarrollo armónico de los seres humanos", por lo que el currículo formal establece la importancia y la necesidad de que los estudiantes reciban una formación no sólo intelectual, sino que atienda de manera holística el desarrollo pleno de su persona, al reconocer su integralidad o corporeidad; ${ }^{2}$ parafraseando a Alicia Grasso (2005), se podría decir que cuando el ser humano se mueve, lo hace como ser total, en el sentido de que al actuar, los individuos movilizan de manera íntegra la totalidad de sus áreas de desarrollo.

Con relación a este planteamiento, a propósito de lograr una verdadera educación integral en el aterrizaje y operación del currículo, para el nuevo Modelo Educativo "Es fundamental la incorporación adecuada de la educación física y el deporte [...] como piezas indispensables en su desarrollo personal y social, en todos los niveles y modalidades

1 De acuerdo con el artículo $3^{\circ}$ constitucional, la educación obligatoria está conformada por la educación básica y la educación media superior.

2 La corporeidad es la construcción permanente de la unidad psicofísica, intelectual, motora, afectiva y social, es decir, del ser humano, a partir de lo que tiene significado e identidad para el alumno. de la educación obligatoria" (SEP, 2017a: 63), es decir, se reconoce curricularmente la práctica de las actividades físicas y deportivas como condición indispensable para alcanzar la formación integral en la educación media superior.

Con relación a los aprendizajes clave para la educación obligatoria (SEP, 2017b: 74), "Una de las principales innovaciones de este planteamiento es la incorporación de las habilidades socioemocionales al currículo formal de toda la educación obligatoria". Es en este tema donde se concentran los aprendizajes relacionados con aspectos artísticos, motrices y socioemocionales. En este orden de ideas, el CEM desarrolla actividades paraescolares con valor crediticio que contribuyen a la formación integral de los estudiantes, por medio de la práctica pedagógica, sistemática y organizada de actividades deportivas principalmente colectivas.

\section{Desarrollo}

A partir del año 2012, al reformarse el artículo tercero y 31 constitucionales ( $D O F)$, por primera vez y de manera histórica en México se incluye dentro de la educación obligatoria a la educación media superior, misma que se consolida con la propuesta curricular para la educación obligatoria de la SEP (2017b). 
Específicamente hablando de la UAA, el Modelo Educativo Institucional (MEI) al respecto refiere que:

El Modelo Educativo de la UAA busca facilitar a los estudiantes de los distintos programas educativos que ofrece la institución, una formación humanista que comprenda el desarrollo equilibrado e integral de las dimensiones de su persona: profesional, intelectual, actitudinal, valoral, física, cultural y social para que puedan desempeñarse profesionalmente con éxito y vivir la vida con plenitud y calidad (UAA, 2007: 7).

La UAA es una comunidad de aprendizajes que piensa y aprende de sus procesos; para la formación integral de sus estudiantes incluye como uno de los pilares importantes las actividades deportivas. En términos del MEI, estas actividades se encuadran dentro de la formación física, en la que "los estudiantes desarrollarán una cultura física que mostrará hábitos de vida saludable, de ahí que se promueva la participación regular y disciplinada en actividades encaminadas a ello" (UAA, 2007: 7).

A este respecto y desde la perspectiva de la praxiología motriz, ${ }^{3}$ es posible distinguir entre juegos y deportes psicomotrices y sociomotrices (Parlebas, 2008): los primeros se realizan de manera individual o en solitario, mientras que los segundos refieren a las actividades de conjunto; lo que supone que su práctica concita una serie de interacciones y condiciones de orden social, mismas que promueven un cúmulo de aprendizajes y desarrollos que, desde el punto de vista psicosocial, impactan positivamente en la construcción de la personalidad.

En este orden de ideas, la sociomotricidad ${ }^{4}$ contribuye a que los participantes o jugadores se puedan expresar en una integración global, como unidad interactuante a partir de las relaciones que establecen con su propio cuerpo, con otras personas y con el medio, utilizando el juego deportivo como elemento didáctico básico. La sociomotricidad representa un escenario de participación social de inclusión, en el que, a través del juego deportivo motor, los participantes se expresan e integran, a través de las relaciones intra e interpersonales que se generan, en las que, como se ha explicado en párrafos anteriores, tiene gran importancia la práctica de los deportes en equipo: baloncesto, futbol, volibol y beisbol, entre otros, por parte de los bachilleres.

3 La praxiología motriz trata del análisis de la práctica de la motricidad.

4 La sociomotricidad hace referencia a una actividad o interacción en la que participan una o más personas, especialmente en los juegos y deportes colectivos.
Dichas actividades deportivas de tipo colectivo colaboran de manera decisiva en la finalidad formativa de la educación física en la educación obligatoria (SEP, 2017b), que es: la edificación de la competencia motriz por medio del desarrollo de la motricidad, la integración de la corporeidad y la creatividad en la acción motriz; y por otro lado, vista como corriente contemporánea (Zagalaz, 2001), la sociomotricidad contribuye significativamente a la construcción de este campo de estudio.

« La sociomotricidad contribuye a que los participantes o jugadores se puedan expresar en una integración global, como unidad interactuante a partir de las relaciones que establecen con su propio cuerpo, con otras personas y con el medio, utilizando el juego deportivo como elemento didáctico básico.》〉

De esta forma, la práctica de la actividad deportiva por parte de los estudiantes del CEM es una oportunidad importante para el despliegue armonioso de todas sus áreas de desarrollo: psicológica, física, intelectual, motora, social y afectiva, mismas que aportan de manera significativa a su formación integral, así como a la construcción de las competencias genéricas del perfil de egreso del CEM, específicamente en lo que respecta al ámbito de la atención al cuerpo y la salud (UAA, 2018). Así, el deporte no sólo es un espacio para el esparcimiento o la diversión, parafraseando a Joffre Dumazedier (1964), el deporte es una actividad de desarrollo o aprendizaje para los estudiantes de este nivel, catalogado como un importante medio educativo en temas de tipo transversal, como: la elección de estilos de vida saludable, la práctica de los valores universales, el desarrollo personal, la convivencia social pacífica, la construcción de ciudadanía, además de la edificación de la competencia motriz. ${ }^{5}$

Por lo mismo, es importante reconocer la actuación didáctica de los docentes del área para promover y alcanzar los logros ya mencionados, ya que, en palabras de Eduardo Andere (2012: 188), "se trata del factor más importante dentro de los factores escolares", e interpretando a Castañer y Camerino (2002): resulta trascendente y categórica la labor del profesor para crear ambientes socializadores de trabajo físico; es así que cobran importancia las situaciones didácticas que privilegian la colaboración y el trabajo entre pares, por el aporte que hacen al desarrollo

5 Saberes puestos en operación para resolver problemas motrices y de la vida cotidiana de las personas. 


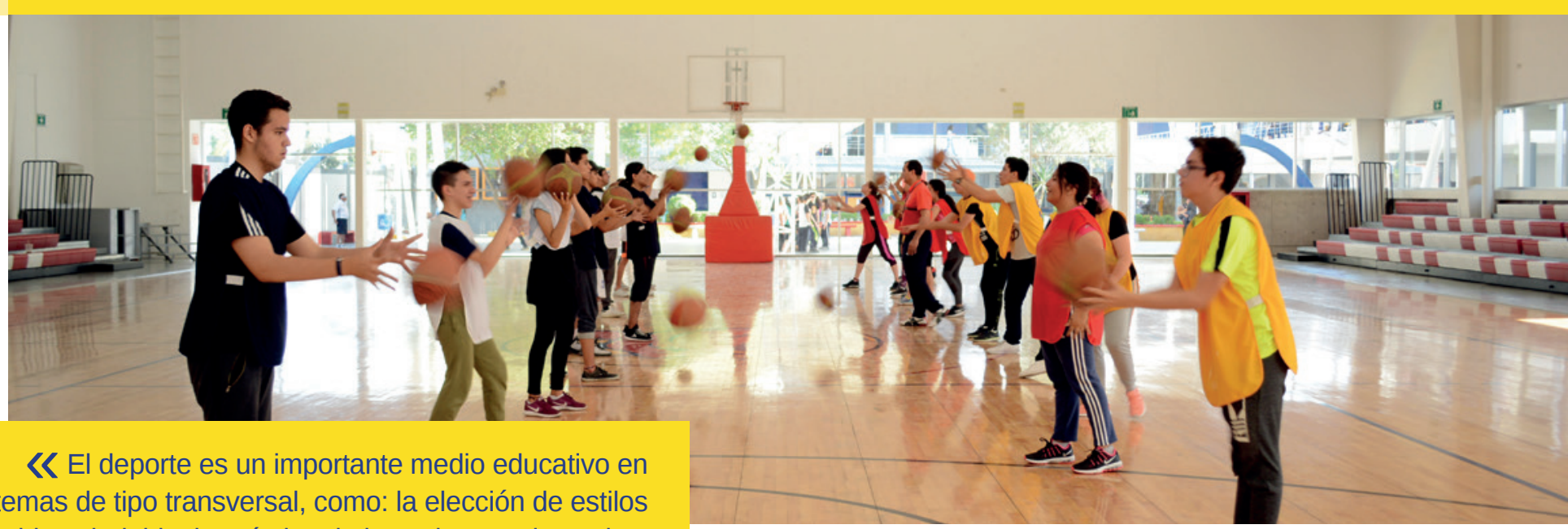
de vida saludable, la práctica de los valores universales,

el desarrollo personal, la convivencia social pacífica, la construcción de ciudadanía. \)

de las capacidades de aprender a ser y aprender a convivir, pues facultan al estudiante para la vida en sociedad.

Por otro lado, el docente debe ser capaz de poner en valor o reconocer las diversas aportaciones del deporte al desarrollo armónico y global de los estudiantes, contar con capacidad reflexiva y crítica para comprender la trascendencia social de su labor formativa, con el propósito de no asumirse como si fuese un entrenador de caballos de carreras, sino como un verdadero educador con una formación técnica y humanista en las áreas del movimiento humano, misma que le permita entender esta visión del desarrollo integral de la persona correspondiente al estudiante universitario.

\section{Conclusión}

Es necesario considerar el hecho de que el deporte es un microcosmos del entorno social donde se desenvuelven los estudiantes, por lo que la práctica sistemática y organizada provee a los mismos de cierto conocimiento que los faculta a transferir las vivencias ocurridas en las situaciones de la práctica del deporte a su vida social, familiar y personal; verbigracia, la aplicación y respeto por las reglas, el ejercicio de la comunicación efectiva, la colaboración para resolver problemas, la actitud de afrontar retos y la canalización positiva de la confrontación, resultado de algunas de las valencias pertenecientes a la práctica del deporte estudiantil.

El más sólido y mejor argumento para sustentar la práctica de los deportes sociomotrices es su contribución a la formación integral de los estudiantes, esto por el uso compensador de su cuerpo y por los beneficios sociales, intelectuales, físicos, motores y emocionales que promueven las actividades de con-

junto, las cuales impactan positivamente en la personalidad de los estudiantes; por otro lado, por su importante aportación en la construcción de las competencias del perfil de egreso de la educación media superior establecidas por el CEM. Por todo lo anterior, se justifica la importancia y necesidad de la práctica del deporte y actividades físicas sociomotrices en la formación integral de los estudiantes del bachillerato de la UAA.

Fuentes de consulta

Andere, E. (2012). El debate. En G. Guevara (Coord.), México 2012: La reforma educativa. México: Ediciones Cal y Arena.

Castañer, M. y Camerino, O. (2002). Introducción a la educación física. México: Secretaría de Educación Pública.

Dumazedier, J. (1964). Hacia la civilización del ocio. Barcelona: Editorial Estela.

Grasso, A. (2005). Construyendo identidad corporal. Argentina: Novedades Educativas.

Parlebas, P. (2008). Juegos, deporte y sociedad. Barcelona: Paidotribo.

SEgob (2012). Constitución Politica de los Estados Unidos Mexicanos. En Diario Oficial de la Federación. México: Secretaría de Gobernación.

SEP (2017a). Aprendizajes clave para la educación integral. México: SEP.

SEP (2017b). Modelo educativo para la educación obligatoria. México: SEP.

UAA (2007). Modelo Educativo Institucional. Correo Universitario, séptima época, No. 15. [Primera reimpresión] 29 de mayo de 2015. México: UAA. Recuperado de: https://bit.ly/2U4GCGo.

UAA (2018). Bachillerato Currículo 2018. Centro de Educación Media. México: UAA-Centro de Educación Media. Recuperado de: https://bit.ly/2U4GCGo.

Zagalaz, M. (2001). Corrientes y tendencias de la educación física. España: INDE. 